\title{
Impact of socio-demographic and clinical characteristics on functional disability and health-related quality of life in patients with rheumatoid arthritis: a cross-sectional study from Palestine
}

\author{
Samah W. Al-Jabi ${ }^{*} \mathbb{B}$, Diaa I. Seleit ${ }^{1}$, Adnan Badran², Amer Koni ${ }^{1,3}$ and Sa'ed H. Zyoud ${ }^{1,4,5}$
}

\begin{abstract}
Background: Rheumatoid arthritis (RA) is a chronic autoimmune disorder, which has a significant impact on patients' health-related quality of life (HRQoL), and limits physical function as well as increases pain and fatigue. Therefore, this study aimed to evaluate the HRQoL and functional disability profile of patients with RA in Palestine to determine the socio-demographic and clinical features associated with low HRQoL and functional disability in patients with RA and to investigate the impact of drugs used on functional disability and HRQOL.
\end{abstract}

Methodology: A cross-sectional, observational study conducted at rheumatology clinics in Northern West-Bank, Palestine (Alwatani Hospital_Nablus, Khalil Suleiman Hospital—Jenin, Thabet Thatbet Hospital-Tulkarem, and Darweesh Nazzal Hospital-Qalqilia). EuroQoL-5 Dimension scale (EQ-5D-5L) was used to evaluate HRQoL, Health Assessment Questionnaire, Disability Index (HAQ-DI) to evaluate the functional disability, and the Health Assessment Questionnaire pain visual analog scale (HAQ-VAS) to evaluate pain.

Results: 300 patients were included in the study, 229(76.3\%) were females, the mean \pm standard deviation age was $49 \pm 13.10$ years, and the median RA duration (lower-upper quartiles) was 6 (4-12) years. The median EQ-5D-5L index value and Euro QOL visual analogue scale (EQ-VAS) scores were 0.56 and 60 , respectively. There was a significant strong positive correlation ( $\mathrm{R}=0.773 ; p<0.001$ ) between the $\mathrm{EQ}-5 \mathrm{D}-5 \mathrm{~L}$ index values and the reported $\mathrm{EQ}-\mathrm{VAS}$ scores. The median HAQ-DI and HAQ-VAS were 0.94 and 40, respectively. The results of multiple linear regression showed that treatment with biological DMARD (Etanercept), having work, higher income, absence of night pain, and absence of comorbid diseases were significantly associated with higher EQ-5D-5L index score (better HRQoL) and lower HAQ-DI scores (less disability). On the other hand, older age and the presence of morning stiffness were significantly associated with higher HAQ-DI scores (more disability).

Conclusions: This study revealed the impact of treatment, clinical variables, and socio-demographic factors on disability and HRQoL in RA patients. Healthcare providers should be aware of the association between treatment with

\footnotetext{
*Correspondence: samahjabi@yahoo.com; samahjabi@najah.edu

${ }^{1}$ Department of Clinical and Community Pharmacy, College of Medicine

and Health Sciences, An-Najah National University, Nablus 44839, Palestine

Full list of author information is available at the end of the article
}

(c) The Author(s) 2021. Open Access This article is licensed under a Creative Commons Attribution 4.0 International License, which permits use, sharing, adaptation, distribution and reproduction in any medium or format, as long as you give appropriate credit to the original author(s) and the source, provide a link to the Creative Commons licence, and indicate if changes were made. The images or other third party material in this article are included in the article's Creative Commons licence, unless indicated otherwise in a credit line to the material. If material is not included in the article's Creative Commons licence and your intended use is not permitted by statutory regulation or exceeds the permitted use, you will need to obtain permission directly from the copyright holder. To view a copy of this licence, visit http://creativecommons.org/licenses/by/4.0/. The Creative Commons Public Domain Dedication waiver (http://creativecommons.org/publicdomain/zero/1.0/) applies to the data made available in this article, unless otherwise stated in a credit line to the data. 
biological DMARD and improved HRQoL and functional status to make early interventions that reduce disability and improve HRQoL in susceptible patients.

Keywords: Functional disability, HRQoL, Quality of life, Rheumatoid arthritis, Palestine

\section{Background}

Rheumatoid arthritis (RA) is a chronic, autoimmune, multisystemic, inflammatory, progressive condition of uncertain etiology characterized by joint pain, swelling, stiffness, and synovial joint destruction, resulting in serious impairment and premature mortality $[1,2]$. It is estimated that it affects between $0.5 \%$ and $1.0 \%$ of the world's adult population and affects women more than men [3].

Rheumatoid arthritis is a troublesome condition that greatly impacts patients' lives; affecting HRQoL and limiting physical function. Fatigue is considered one of the deliberating outcomes among all chronic diseases. This impacts patients' involvement in paid jobs, their work performance within and outside the home, and their participation in family, social, and leisure activities [4].

In RA treatment, assessing health-related quality of life (HRQoL) and functional status has become an important complement to clinical, laboratory, and functional indicators in evaluating patients [5-7]. Moreover, maximizing HRQoL and maintaining physical function are treatment goals, besides early detection, intervention, controlling disease activity, and alleviating pain $[6,8]$.

Several tools have been proposed to evaluate the HRQoL and disability in patients with RA, including both generic tools, such as the Medical Outcomes Study 36-Item Short-Form Health Survey (SF-36), and European Quality of Life-5 Dimensions (EQ-5D); and specific tools, such as Rheumatoid Arthritis Quality of Life Scale (RAQoL), and the Health Assessment Questionnaire (HAQ) [9, 10]. Improvements in RA patients are identified by both disease-specific and standardized tests of function and HRQoL. The use of both forms of therapy evaluation measures can help recognize subtle changes that are important to patients and promote similarities between various disease states [11].

Rheumatoid arthritis disease is not being cured using the available treatment; the treatment administered can manage and control at a minimum level the disease effect on RA patients by increasing HRQoL [12]. In addition, it has been indicated that HRQoL can be considered as one of the most important components of the quality of medical and health care [13]. Few studies assessed HRQoL in Palestinian patients with other medical conditions rather than RA [14-21], and no study has assessed patients' disability in a specific disease. Despite the importance of HRQoL and the degree of disability in patients with RA, no previous studies have been carried out to the best of our knowledge to determine HRQoL or disability in patients with RA in Palestine. However, some studies have been carried out worldwide, and few regional studies have been carried out [22-33].

Therefore, this study has been conducted to conclude and provide a general and clear view of RA patients' HRQoL and disability in Palestine. In addition, the results of this study can be used in planning and interventions for improving RA patients' HRQoL and reducing their disability. It also aims to determine the socio-demographic characteristics and clinical factors associated with poor HRQoL and functional disability of RA patients and investigate the effect of medications used on functional disability and HRQoL.

\section{Methods}

\section{Study design and settings}

This study is an observational cross-sectional study that included all rheumatology clinics in the government hospitals of the Northern West-Bank, Palestine. The clinics included in the study were at Alwatani Hospital-Nablus, Khalil, Suleiman Hospital-Jenin, Thabet, Thatbet Hospital-Tulkarem, and Darweesh Nazzal Hospital-Qalqilia. These clinics are working just 1 day per week by the same rheumatologist on consecutive days. They are the main care providers for RA patients in Palestine's geographical area, with approximately more than one million residents. The clinics where the study was carried out offer medical care, including rheumatologist examination, laboratory tests, radiologic imaging, and prescribing medications to be dispensed later in primary health care clinics.

\section{Sample size}

According to data from the rheumatology clinics and the Palestinian Health Information Center, approximately 1042 RA patients were referred to the rheumatology clinics in Northern West-Bank, Palestine in the year 2012. In addition, Alwatani Hospital-Nablus received approximately $31.2 \%$ of the total visits, followed by Khalil Suleiman Hospital-Jenin (30.8\%), Thabet Thatbet Hospital-Tulkaram (24\%), and Darweesh Nazzal HospitalQalqilia (14\%). Thus, according to these numbers, the sample size was calculated depending on the sample size calculator by Raosoft. The minimum effective sample size calculated for this investigation was 281 RA patients, based on a response distribution of $50 \%$ for patients with 
low HRQoL or functional impairment and a 5\% margin of error at the $95 \%$ confidence interval. In addition, to decrease false results and maximize the reliability of the current study, the estimated sample size was increased by $5-10 \%$.

\section{Data collection}

Data was collected by a clinical pharmacist who is a primary health care team member and is familiar with the work system at clinics. All patients that presented at the clinic on the day that the clinical pharmacist was there approached to participate in the study were reviewed and chosen conveniently. Data was collected 4 days per week, from March to June 2014. The researcher who was in charge reached the clinic, remained in the clinic throughout the working time, interviewed each patient for at least $15 \mathrm{~min}$, and assessed patients' profiles. To assess the reliability and validity of the data collection form, a pilot test with 20 patients was carried out. Patients who participated in the pilot study were excluded from the target study sample.

\section{Tools used in data collection}

A data collection form consists of four parts. The first part contains the socio-demographic characteristics, including age, gender, height, weight, residency, education level, marital status, work and employment status, family monthly income, and cigarette smoking.

The second part contains disease-related characteristics including age at onset, length of RA, duration (years), presence of delayed diagnosis (defined as a delay in time between the onset of symptoms and the beginning of treatment (months)), encountering of night pain (number of awakenings), morning stiffness (minutes), comorbid diseases, and medication used (corticosteroids, DMARDs, and biological agents).

The third part contains the European Quality of Life 5-Dimensions scale (EQ-5D-5L). We used EQ-5D-5L version, which were created in 2009 to improve the tool's sensitivity, compared to the $3 \mathrm{~L}$ version [34]. The EQ5D-5L consists of a 5 -item descriptive system to measure the EQ-5D-5L index and the EQ visual analogue scale (EQ-VAS) to estimate the patients' current health status from zero to one hundred [34]. The Arabic version of EQ-5D-5L seems to be reliable and valid in estimating HRQoL [35]. Moreover, the Cronbach's alpha value of the EQ-5D-5L instrument in the current study was found to be 0.88 ; that showed the high reliability of the EQ-5D-5L instrument.

The fourth part of the data collection form contains the HAQ-DI, which was used to evaluate the functional disability. HAQ-DI is the main frequent scale used for assessing functional status and disability in RA patients
[36-39]. The Arabic HAQ is a reliable and valid instrument that can be self-administered to Arabic RA patients to evaluate their functional disability [40]. Moreover, the Cronbach's alpha value of the HAQ-DI tool in the current study was found to be 0.90 ; that showed the high reliability of the HAQ-DI tool. The scale includes 20 items that describe the difficulty that encounters respondents in their usual daily activities. In addition, the HAQ-DI score ranges from 0 (no disability) to 3 (greatest disability) and sets patients into one of three categories (mild, moderate, and severe disability) [36-38, 41].

The final section consists of the HAQ-VAS Pain Scale. This scale obtained information on how RA patients felt pain over the past week. It horizontal VAS with endpoints labeled from zero (no pain) to one hundred (worst pain) [41].

\section{Inclusion and exclusion criteria}

The Inclusion criteria for this were as follows: (1) patients with confirmed RA diagnosis (according to the American College of Rheumatology Criteria) for at least six months and visiting rheumatology clinics in Northern WestBank, Palestine; (2) patients who were 18 years old and above; and (3) Patients who agreed to participate. This study's exclusion criteria were as follows: (1) patients who have necrotic vascular disease, or they were handicapped prior to RA [42]; and patients who were not treated.

\section{Ethical approval}

Before the start of the research, the Institutional Review Board (IRB)'s approval, the permission of local health authorities, and the Faculty of Graduate Studies' agreement at An-Najah National University were received to ascertain patients' rights and facilitate the research progression. Only patients who agreed to participate were included in the study after discussing the research objectives and protocols and obtaining a verbal agreement.

\section{Statistical data analysis}

All data were analyzed using the Statistical Package for Social Sciences (SPSS) (SPSS Inc., Chicago, IL, USA) program version 16 . The descriptive analysis presented normally distributed continuous variables as means \pm standard deviation (SD), not normally distributed continuous variables as medians (lower-upper quartiles), and categorical variables as frequencies and percentages. Kolmogorov-Smirnov test was used to assess data normality. Differences in score results were evaluated using the $\mathrm{t}$-test for continuous variables (normally distributed). The Mann-Whitney U test or Kruskal-Wallis has performed appropriately for not normally distributed ones. Either the Chi-square or the Fisher exact test was used, as appropriate, to test the 
significance between categorical variables. The correlation was assessed using Spearman's correlation coefficient. Multiple linear regression was used to estimate which variables were significantly related to HRQoL. Dummy variables were created for categorical variables to include them in the multiple linear regression. On the other hand, the reliability of the study scales was assessed using Cronbach's alpha values. The level of significance was determined at $p<0.05$. In addition, the scores of EQ$5 \mathrm{D}-5 \mathrm{~L}$ were calculated depending on values taken from the United Kingdom general population using the EQ5D-5L Crosswalk Index Calculator (http://www.euroqol. org/about-eq-5d/valuation-of-eq-5d/eq-5d-5l-value-sets. html accessed August 2014). United Kingdom tariff for the EQ-5D-5L was used to derive the EQ-5D-5L index values as Palestinian tariff was not available. It was also used in previous publications conducted in Palestine [14, $17,21,43,44]$.

\section{Results}

Socio-demographic characteristics of the study patients

A total number of 300 patients with RA were included in this study. Table 1 shows the socio-demographic characteristics of the patients. The mean age $( \pm S D)$ of the patients was $49 \pm 13.1$ years, ranging from 18 to 89 . The majority of patients were females (76.3\%), giving a female: male ratio of 3.2:1. In addition, $183(61 \%)$ patients were living in villages, and 91 (30.3\%) were living in urban areas.

\section{Clinical characteristics of RA patients}

Table 2 shows the RA related clinical characteristics of patients. The mean $( \pm S D)$ age of RA onset was $40.61 \pm 13.44$ years, with a range from 10 to 77 years. Among the patients included, 192 (64\%) patients had a delayed diagnosis; 186 patients of them had a median (interquartile range) duration of delay of 12 (4-12) months. Regarding their daily symptoms, the majority of patients $(65.3 \%)$ had morning stiffness. In addition, 196 (65.3\%) patients had night pain affecting their sleep, causing awakenings each night. Regarding the presence of other comorbid diseases, $172(57.3 \%)$ patients had comorbid conditions.

\section{Medications used among RA patients}

Methotrexate was the most commonly used conventional DMARD; it was used by $224(74.4 \%)$ patients, followed by Leflunomide (17\%), hydroxychloroquine (11.3\%), sulfasalazine (5.3\%), and azathioprine (4\%). In addition, regarding biotherapy, 37 (12.3\%) patients received etanercept, either alone or in combination with conventional DMARDs. In addition, prednisolone was used in
Table 1 Socio-demographic characteristics of the study patients $(\mathrm{N}=300)$

\begin{tabular}{|c|c|}
\hline Variable & $\begin{array}{l}\text { Mean } \pm \text { SD (range) } \\
\text { Or } \\
\mathrm{N}(\%) \\
\text { Total }=300\end{array}$ \\
\hline Age (year) & $49 \pm 13.10(18-89)$ \\
\hline \multicolumn{2}{|l|}{ Rheumatology clinic } \\
\hline Nablus & $94(31.3 \%)$ \\
\hline Jenin & $93(31 \%)$ \\
\hline Tulkarm & $72(24 \%)$ \\
\hline Qalqilia & $41(13.7 \%)$ \\
\hline \multicolumn{2}{|l|}{ Gender } \\
\hline Male & $71(23.7)$ \\
\hline Female & $229(76.3)$ \\
\hline \multicolumn{2}{|l|}{ Residency } \\
\hline City & $91(30.3)$ \\
\hline Village & $183(61)$ \\
\hline Refugee camp & $26(8.7)$ \\
\hline \multicolumn{2}{|l|}{ Conjugal status } \\
\hline With a spouse/partner & $233(77.7)$ \\
\hline Without a spouse/partner & $67(22.3)$ \\
\hline Single & $46(15.3)$ \\
\hline Divorced & $5(1.7)$ \\
\hline Widowed & $16(5.3)$ \\
\hline \multicolumn{2}{|l|}{ Level of education } \\
\hline Illiterate & $33(11)$ \\
\hline Primary & $128(42.7)$ \\
\hline Secondary & $81(27)$ \\
\hline University & $58(19.3)$ \\
\hline \multicolumn{2}{|l|}{ Employment status } \\
\hline Working & $79(26.3)$ \\
\hline Employee & $41(13.7)$ \\
\hline Private job & $38(12.7)$ \\
\hline Not working & $221(73.7)$ \\
\hline Unemployed & $18(6)$ \\
\hline Housewife & $203(67.7)$ \\
\hline \multicolumn{2}{|l|}{ Income (NIS) } \\
\hline Low (Less than 2000) & $133(44.3)$ \\
\hline Moderate (2000-5000) & $167(55.7)$ \\
\hline High (More than 5000) & $2(0.7)$ \\
\hline \multicolumn{2}{|l|}{$B M l$} \\
\hline Normal (18.5-24.9) & $104(34.7)$ \\
\hline Overweight (25-29.9) & $105(35)$ \\
\hline Obese (30 or greater) & $91(30.3)$ \\
\hline \multicolumn{2}{|l|}{ Smoking } \\
\hline Current smoking & $22(7.3)$ \\
\hline Never smoke & $258(86)$ \\
\hline Ex-smoker & $20(6.7)$ \\
\hline
\end{tabular}

$B M I$ body mass index, NIS new Israeli shekel, SD standard deviation 
Table 2 Clinical characteristics of the study patients

\begin{tabular}{ll}
\hline Variable & Mean \pm SD \\
& Median (lower-upper quartile) \\
& Or \\
& $\mathrm{N}(\%)$ \\
& Total $=300$
\end{tabular}

\begin{tabular}{lc}
\hline Age of RA onset (years) & $40.61 \pm 13.44(10-77)$ \\
RA duration (years) & $6(4-12)$ \\
Diagnosis delay & $192(64)$ \\
Delay & $108(36)$ \\
No delay & $12(4-12)$ \\
Delay diagnosis (months) & \\
Morning stiffness & $196(65.3)$ \\
Stiffness & $104(34.7)$ \\
No stiffness & $15(10-30)$ \\
Morning stiffness (minutes) & \\
Night pain & $196(65.3)$ \\
Pain & $104(34.7)$ \\
No pain & $2(2-3)$ \\
Number of awakenings & $172(57.3)$ \\
Comorbid diseases & $128(42.7)$ \\
Yes & $2(1-2)$ \\
No & \\
Number of comorbid diseases & $75(25)$ \\
Number of comorbid diseases & $55(18.3)$ \\
1 & $24(8)$ \\
2 & $12(4)$ \\
3 & $6(2)$ \\
5 &
\end{tabular}

$R A$ rheumatoid arthritis

${ }^{\text {a }}$ Data for delayed diagnosis were only available for 186 patients

most therapeutic plans; $260(86.7 \%)$ patients received it (Table 3).

\section{EQ-5D-5L index score}

The median of the EQ-5D-5L index was 0.56 (IQR: $0.33-0.74)$. Patients aged more than 60 years significantly had the lowest EQ-5D-5L index score $(p<0.001)$. Male patients had a significant higher median EQ-5D-5L index score than females $(p<0.001)$. Patients with a higher level of education, employed patients, and those with moderate or high income had significantly higher median EQ-5D-5L index scores. Regarding residency; patients living in refugee camps had significant higher median EQ-5D-5L index scores than those living in cities or patients living in villages $(p=0.018)$ (Additional file 1 : Table S1).

Furthermore, patients who complained of morning stiffness, night pain, comorbid diseases, or had a delay in
Table 3 medications used to treat RA patients

\begin{tabular}{ll}
\hline Variable & $\begin{array}{l}\text { Mean } \pm \text { SD (range), } \\
\text { median (lower-upper } \\
\text { quartile) } \\
\text { Or } \\
\text { N (\%) } \\
\text { Total }=\mathbf{3 0 0}\end{array}$ \\
& \\
& $260(86.7)$ \\
\hline Medications & $279(93)$ \\
Corticosteroids (Prednisolone) & $224(74.4)$ \\
DMARDs & $51(17)$ \\
Methotrexate & $34(11.3)$ \\
Leflunomide & $16(5.3)$ \\
Hydroxychloroquine & $12(4)$ \\
Sulfasalazine & $37(12.3)$ \\
Azathioprine & \\
Biotherapies (Etanercept) & $202(67.3)$ \\
Therapeutic plan & $61(20.3)$ \\
Single DMARD & $22(7.3)$ \\
Combination of 2 DMARDs & $15(5)$ \\
Biotherapy (Etanercept) & \\
Combination of Etanercept and DMARD & \\
\hline
\end{tabular}

diagnosis had significantly lower median values of EQ5D-5L index score (Additional file 1: Table S2).

On the other hand, patients treated with the biological agent (Etanercept) had significant higher median EQ$5 \mathrm{D}-5 \mathrm{~L}$ values $(p<0.001)$. However, patients treated with conventional DMARDs had significantly lower median values of EQ-5D-5L $(p<0.001)$. Regarding the therapeutic plan, the patients followed it; the results showed that patients using a biological agent (Etanercept) significantly had the highest EQ-5D-5L median score $(0.82(0.73-1))$ (Additional file 1: Table S3).

On the other hand, the results show a significantly weak negative association between EQ-5D-5L index values and RA duration $(\mathrm{R}=-0.167 ; p=0.006)$, In addition to, age of $\mathrm{RA}$ onset $(\mathrm{R}=-0.158 ; p=0.006)$.

\section{EQ-visual analogue (VAS)}

The median of EQ-VAS was 60 (IQR: 50-77.5). Older patients significantly had the lowest EQ-5D-5L index score $(p<0.001)$. Significant differences were also shown in variables such as gender $(p<0.001)$ and BMI $(p<0.001)$. Furthermore, treatment with the biological agent (Etanercept) was significantly associated with higher median values of VAS $(p<0.001)$.

\section{Correlation between the EQ-5D-5L index and EQ-VAS}

The EQ-5D-5L index was significantly and positively correlated $(\mathrm{R}=0.773 ; p<0.001)$ with the reported EQ-VAS scores. 
Multiple linear regression analysis for $\mathrm{HRQ}$ oL

Further analysis was done using multiple linear regression to examine which variables were significantly related to HRQoL ( $\mathrm{R}=0.654$; adjusted $\mathrm{R} 2=0.418 ; \mathrm{F}=15.7$; $\mathrm{df}=13 ; p<0.001)$. Table 4 shows that treatment with biological DMARD (Etanercept), work, higher income, and absence of night pain, absence of comorbid diseases were significantly associated with higher EQ-5D-5L index score (better HRQoL).

\section{Disability of RA patients}

According to HAQ-DI scores, the median (interquartile range) of HAQ-DI scores was 0.94 (0.5-1.5). According to HAQ-DI categories, patients were categorized into three categories (mild to moderate, moderate to severe, and severe to very severe disability). Our data shows that half of the patients $(50.0 \%)$ had mild to moderate disability. Disability was significantly associated with morning stiffness $(p<0.001)$, night pain $(p<0.001)$, and comorbid diseases $(p<0.001)$ (Additional file 1: Table S4).

Of note, patients treated with the biological agent (Etanercept) were having less disability significantly $(p<0.001)$. However, treatment with conventional DMARDs had significant severe to very severe disability $(p=0.003)$. Concerning the treatment strategy, patients using a combination of a biological agent (Etanercept) and conventional DMARDs or those who were using a biological agent (Etanercept) alone significantly complained of mild to moderate disability $(p<0.001)$ (Additional file 1: Table S5). Moreover, the results show a significantly weak positive association between HAQDI and RA duration $(\mathrm{R}=0.191 ; p=0.001)$. In addition, a significantly moderate positive association was found between HAQ-DI and age of RA onset $(\mathrm{R}=0.324$; $p<0.001)$.

\section{Multiple linear regression analysis for disability}

To assess which variables were significantly related to HAQ-DI scores, multiple linear regression analysis was applied $(\mathrm{R}=0.666$; adjusted $\mathrm{R} 2=0.418 ; \mathrm{F}=17.5 ; \mathrm{df}=13$; $p<0.001)$. Significantly associated with higher HAQ-DI scores (disabled) were found in the following factors: older patients, being without work, lower income, presence of morning stiffness, presence of night pain, presence of comorbid diseases, and patients not treated with biological DMARD (Etanercept) (Table 5).

\section{HAQ-VAS pain scale}

The median of HAQ-VAS pain was 40 (IQR: 20-50). There was a significantly strong negative correlation $(\mathrm{R}=-0.622 ; p<0.001)$ between the HAQ-VAS pain scores and the reported EQ-VAS scores. Furthermore, a significantly strong positive association was observed
Table 4 Association between factors and EQ-5D-5L score using multiple linear regression analysis

\begin{tabular}{|c|c|c|}
\hline Variables & $\begin{array}{l}\text { Standardized } \\
\text { coefficients (beta) }\end{array}$ & $p$ value \\
\hline \multicolumn{3}{|l|}{ Age } \\
\hline Continuous (1-year units) & -0.082 & 0.124 \\
\hline \multicolumn{3}{|l|}{ Gender } \\
\hline Male & 0.083 & 0.174 \\
\hline Female & Ref & \\
\hline \multicolumn{3}{|l|}{ Body mass index } \\
\hline Normal & -0.053 & 0.309 \\
\hline Overweight or obese & Ref & \\
\hline \multicolumn{3}{|l|}{ Residency } \\
\hline City & 0.084 & 0.076 \\
\hline Others & Ref & \\
\hline \multicolumn{3}{|l|}{ Work status } \\
\hline Unemployed & -0.135 & 0.036 \\
\hline Employed & Ref & \\
\hline \multicolumn{3}{|l|}{ Income } \\
\hline Moderate and High & 0.148 & 0.004 \\
\hline Low & Ref & \\
\hline \multicolumn{3}{|l|}{ Education } \\
\hline University & 0.034 & 0.586 \\
\hline No formal, primary, secondary & Ref & \\
\hline \multicolumn{3}{|l|}{ Diagnosis delay } \\
\hline No & 0.072 & 0.132 \\
\hline Yes & Ref & \\
\hline \multicolumn{3}{|l|}{ Morning stiffness } \\
\hline No & 0.076 & 0.185 \\
\hline Yes & Ref & \\
\hline \multicolumn{3}{|l|}{ Nightpain } \\
\hline No & 0.276 & $<0.001$ \\
\hline Yes & Ref & \\
\hline \multicolumn{3}{|l|}{ Comorbid diseases } \\
\hline No & 0.211 & $<0.001$ \\
\hline Yes & Ref & \\
\hline \multicolumn{3}{|l|}{ Conventional DMARDs } \\
\hline No & -0.033 & 0.603 \\
\hline Yes & Ref & \\
\hline \multicolumn{3}{|l|}{ Etanercept use } \\
\hline No & -0.153 & 0.017 \\
\hline Yes & Ref & \\
\hline
\end{tabular}

DMARDs disease-modifying antirheumatic drugs, $E Q-5 D$ European Quality of life scale, SE standard error

between HAQ-DI and HAQ-VAS for pain $(\mathrm{R}=0.661$; $p<0.001)$.

\section{Relationship between HRQoL and disability scores}

This study revealed a significant strong negative association between HRQoL and disability (HAQ-DI), according 
Table 5 Association between factors and HAQ-DI score using multiple linear regression analysis

\begin{tabular}{|c|c|c|}
\hline Variables & $\begin{array}{l}\text { Standardized } \\
\text { coefficients (beta) }\end{array}$ & $p$ value \\
\hline \multicolumn{3}{|l|}{ Age } \\
\hline Continuous (1-year units) & 0.226 & $<0.001$ \\
\hline \multicolumn{3}{|l|}{ Gender } \\
\hline Male & -0.047 & 0.429 \\
\hline Female & Ref & \\
\hline \multicolumn{3}{|l|}{ Body mass index } \\
\hline Normal & 0.029 & 0.566 \\
\hline Overweight or obese & Ref & \\
\hline \multicolumn{3}{|l|}{ Residency } \\
\hline City & -0.056 & 0.227 \\
\hline Others & Ref & \\
\hline \multicolumn{3}{|l|}{ Work status } \\
\hline Unemployed & 0.127 & 0.042 \\
\hline Employed & Ref & \\
\hline \multicolumn{3}{|l|}{ Income } \\
\hline Moderate and high & -0.130 & 0.010 \\
\hline Low & Ref & \\
\hline \multicolumn{3}{|l|}{ Education } \\
\hline University & 0.001 & 0.990 \\
\hline No formal, primary, secondary & Ref & \\
\hline \multicolumn{3}{|l|}{ Smoking } \\
\hline No & -0.078 & 0.084 \\
\hline Yes & Ref & \\
\hline \multicolumn{3}{|l|}{ Morning stiffness } \\
\hline No & -0.157 & 0.005 \\
\hline Yes & Ref & \\
\hline \multicolumn{3}{|l|}{ Night pain } \\
\hline No & -0.148 & 0.008 \\
\hline Yes & Ref & \\
\hline \multicolumn{3}{|l|}{ Comorbid diseases } \\
\hline No & -0.218 & $<0.001$ \\
\hline Yes & Ref & \\
\hline \multicolumn{3}{|l|}{ Conventional DMARDs } \\
\hline No & -0.009 & 0.888 \\
\hline Yes & Ref & \\
\hline \multicolumn{3}{|l|}{ Etanercept use } \\
\hline No & 0.164 & 0.009 \\
\hline Yes & Ref & \\
\hline
\end{tabular}

DMARDs disease-modifying antirheumatic drugs, HAQ-DI health assessment questionnaire disability index, SE standard error

to EQ-VAS $(\mathrm{R}=-0.800 ; p<0.001)$ and EQ-index $(\mathrm{R}=-0.775 ; p<0.001)$.

\section{Discussion}

The present study introduced extensive information about HRQoL and functional disability among RA patients in the Northern West Bank, Palestine. HRQoL and disability were estimated using the EQ-5D-5L and HAQ-DI, respectively. Referring to the literature, EQ5D-5L has been used to evaluate HRQoL in RA patients, and it is valid, reliable, and responsive in both specific and general disease populations. HAQ-DI is the most frequently used scale of disability in RA patients.

The mean age of our sample was 49 years, $77 \%$ were married, and $7.3 \%$ were smokers. The majority of patients were females $(76.3 \%)$, giving a female: male ratio of $3.2: 1$, with a median disease duration of 6 years. Palestinians belong to Arabic nations, and the state of Palestine locates in the Middle East and North Africa region. The reported prevalence of RA in this region was $0.16 \%$, with an estimation of RA distribution among genders being 3:1 [45], which is similar to our sample. The characteristics of the RA in the United Arab Emirates previous study were as follows: $4: 1$ female to male ratio, $11 \%$ were smokers, and 89\% were married [46]. In the Saudi Arabia study, $85.6 \%$ of the patients were female, 40.49 years was the mean age, with a mean disease duration of 5.51 years [47].

Notably, age, gender, pain, income, education level, employment status, social status, and body mass index were all previously noted to impact the quality of life of rheumatoid arthritis patients [27, 48-50]. In addition, other factors such as disease activity, depression, tiredness, anxiety, sleep duration, psychological counseling, and $\mathrm{C} 4$ and IgA levels also influence the QoL of RA patients [27, 48].

In the current study, numerous patients' characteristics were found to be related to poor HRQoL in RA patients, such as not working, low income, pain, comorbid diseases, and nonbiological DMARDs use. Furthermore, although residents of refugee camps have higher EQ-5D-5L index values than urban or rural residents, confounding characteristics might affect the EQ-5D-5L index. Additionally, a small number of patients $(n=26$; $8.7 \%$ ) who reside in refugee camps were included in our sample.

In this study, the median of EQ-5D-5L scores among RA patients was 0.56 , while results from previous studies that used the EQ-5D-5L in Danish, Hungarian, Korean, Japanese, and Swedish patients were 0.72 [51], 0.46 [52], 0.60 [53], 0.76[54], and 0.60[55], respectively. The median of EQ-VAS scores was 60. Moreover, the scores of EQVAS were strongly and positively correlated to EQ-5D-5L index values. Using different measures such as the EQ5D-5L and EQ-VAS to assess individual experience may result in slightly different outcomes, and accuracy 
in outcomes when using EQ-5D-5L is probable than EQ-VAS[14].

On the other hand, the current data showed that being unemployed or with low income was significantly associated with lower HRQoL. These results were emphasized in previous studies and considered a significant variable that may deteriorate HRQoL in RA patients [48, 56-59]. Gamal et al. [59] mentioned that working is an advantage for individuals as it makes them able to earn income and gives a sense of accomplishing activities that contribute to society. Importantly, this factor seems to be confounder as poor quality of life might be why patients with RA leave the labor force.

The present results revealed that a higher pain degree was related to lower HRQoL. This result was supported by previous studies [23, 48, 53]. The findings demonstrated that night pain, evaluated by the number of sleep awakenings, was related to lower HRQoL. Purabdollah et al. [60] and Sariyildiz et al. [61] found that sleep problems negatively affected HRQoL in RA patients. A possible explanation is that sleep disturbances are affected by age, disease activity, functional disability, duration of morning stiffness, and the presence of these factors lower HRQoL in RA patients [61]. As for clinical factors, HRQoL was worsened by the existence of comorbidities. A similar relation was confirmed in previous studies [49, 56, 57]. Moreover, comorbid conditions may affect the selection of therapy regimen, or the used medications may deteriorate the comorbidity [62].

The current findings revealed that patients managed with the biological DMARD, etanercept, had higher HRQoL than patients treated with conventional DMARDs. Similar results were observed in other studies $[2,57,63]$. Moreover, patients who were refractory to conventional DMARDs had improvements in HRQoL with the use of biological DMARDs [64, 65]. Furthermore, regarding the combination of etanercept with methotrexate, the results showed that the combination of etanercept with methotrexate was having higher HRQoL than other therapeutic strategies. However, in a previous study, combining etanercept with methotrexate in the treatment regimen was mostly superior to either monotherapy in improving HRQoL [66].

In the current research, elderly, unemployment, lowincome, morning stiffness, night pain, comorbid diseases, nonbiological DMARDs use were all predictors of poor functional disability.

Regarding HAQ-DI scores, the average score that has been reported in RA patients is 1.2 [41]. In the current study, it has been found that the median HAQ-DI score among RA patients was 0.94, while the scores from studies that used HAQ-DI in Egyptian patients were 1.08[67] and 1.45 [68]. In Moroccan patients, the median HAQ-DI scores among RA patients were 1.40[69], and 1.63 [23], while in Tunisian patients, the score was 1.7 [70].

In the current study, it has been found that older RA patients had worse disability than younger ones, which was relevant to previous studies [71-76]. A possible explanation for this finding was that older RA patients had a longer duration of the disease and more comorbid conditions [77], and these characteristics worsen the functional status.

In the current study, the presence of morning stiffness was associated with lower functional status. This result was observed in previous researches $[78,79]$. Night pain, evaluated by the number of sleep awakenings, was associated with functional disability $[61,80]$. Sleep problems in RA sufferers may result from pain, depression, and more active RA [81], and these factors participate in the worsening of disability in RA patients.

As for clinical factors, the presence of comorbidity was found to be related to disability. A similar finding was observed in previous studies [76, 82, 83]. Comorbid conditions are more common in the elderly population. Moreover, patients suffering from multiple comorbidities were treated less aggressively, or prescribed drugs may worsen their comorbidities [62].

On the other hand, the present study indicated that patients treated with the biological DMARD, etanercept, had less disability than patients treated with conventional DMARDs. This result was in agreement with the result in Genovese et al. [84] study. Moreover, etanercept therapy significantly improved disability in RA patients after failure of conventional DMARD therapy [85-87].

Palestinian health care providers should pay more attention to certain patients' characteristics, such as age, income status, and comorbid diseases. In general, biological DMARDs could be offered to a larger number of RA patients in accordance with risk, benefit, and cost assessment, as QoL and disability are important outcomes in these populations. Moreover, extensive research should be conducted to evaluate the use of biological DMARDs in RA, considering other important factors affecting the intended outcomes. In Palestine, the choice of treatment regimen depended on the availability of medications and, to some extent, the overall cost, as Palestine is under occupation and not all materials were easily accessible. That, unfortunately, biological DMARDS could not be reasonable for many RA patients.

Since 2014 and until now, some changes have occurred in the status of RA in Palestine. First, the number of rheumatologists has increased, which helped improve the awareness of RA among the general public and health care practitioners that resulted in early diagnosis of the disease. Additionally, new medications have become available at the Palestinian Ministry of Health. 


\section{Strengths and limitations}

To the extent of our knowledge, this research is the first in Palestine regarding RA and its impact on HRQoL and functional disability, providing a clear view into an unstudied field and initiating a database for future studies focusing on RA patients in Palestine. The study included all RA centers in the northern West Bank of Palestine using the target sample size. Furthermore, the data were recruited via face-to-face interview, giving complete data.

However, the current study had some limitations. First, because of the cross-sectional design, we could not determine a causal relationship between treatment effects, e.g., DMARDs, and the outcomes. Second, the sample population was selected by a convenience sampling method that may affect results generalization. Third, a limitation of the face-to-face interview is the presence of bias as patients may wish to give a private response. However, face-to-face interviews have some advantages: they give more accurate screening, keep the patient-focused while answering, capture verbal and nonverbal cues, and capture behavior and emotions. In addition, the quality of the questions of this study can be answered without any embarrassment. Fourth, some limitations were associated with a poor recall of RA patients' experiences. Lastly, the study lacked some clinical variables such as laboratory tests, disease activity measures, and imaging findings. Their presence might give more data about RA in Palestine and reveal possible factors related to functional status or HRQoL in RA patients.

\section{Conclusions}

The current study was designed to evaluate functional disability and HRQoL among RA patients, determine factors related to disability and poor HRQoL, and assess treatment regimens' influence on disability and HRQoL. The results revealed many important factors that must be considered when providing care to RA patients.

The study found that the median EQ-5D-5L index scores in RA patients were approximately half the total score. In addition, work, higher income, absence of night pain, absence of comorbid diseases, and treatment with biological DMARD (Etanercept) were significantly associated with higher EQ-5D-5L index score (better HRQoL). In addition, it has been found that the disability score (HAQ-DI score) among RA patients was high. Furthermore, older patients, being without work, lower income, presence of morning stiffness, presence of night pain, presence of comorbid diseases, and patients not treated with biological DMARD (Etanercept) were significantly associated with higher HAQ-DI scores (disabled). On the other hand, patients with poor HRQoL were more disabled.
Based on our findings, we recommend: (1) recommend routine assessment of HAQ-DI or EQ-5D-5L to detect changes through the course of RA and the need for intensive treatment; (2) rheumatologists, clinical pharmacists, and other healthcare workers should be aware of the association between treatment with biological DMARD and improved HRQoL and functional status, to make early interventions that reduce disability and improve HRQoL in susceptible patients; and (3) future studies regarding RA should be encouraged to burden the knowledge in this field, to investigate the effect of unstudied factors on HRQoL and functional status among RA patients, and to cover other geographical regions in Palestine.

\section{Abbreviations}

IRB: Institutional Review Board; ACR: The American College of Rheumatology; AIMS2-SF: Arthritis Measurement Scale 2-Short Form; ACPA: Anti-citrullinated protein, antibody; BMI: Body mass index; CDMARDs: Combination diseasemodifying antirheumatic drugs; Cl: Confidence interval; CRP: C-reactive protein; DAS: Disease activity scores; DMARDs: Disease-modifying antirheumatic drugs; EQ-5D: European Quality of Life-5 Dimensions; EQ-VAS: The European Quality Visual Analogue Scale; ESR: Erythrocyte sedimentation rate; EULAR: The European League Against Rheumatism; HAQ: Health Assessment Questionnaire; HAQ-DI: Health Assessment Questionnaire Disability Index; HAQ-VAS: Health Assessment Questionnaire Visual Analogue Scale; HRQoL: Health Related Quality of Life; MDHAQ: Modified Health Assessment Questionnaire; NIS: New Israeli Shekel; OA: Osteoarthritis; OR: Odds ratio; RA: Rheumatoid arthritis; RAQoL: Rheumatoid Arthritis Quality of Life Scale; RF: Rheumatoid factor; SD: Standard deviations; SF-12v2: The Short Form 12 Items (Version 2) Health Survey; SF-36: Medical Outcomes Study 36-Item Short-Form Health Survey; SPSS: Statistical Package for Social Sciences; TNFi: Tumor necrosis factor inhibitors; WHO: World Health Organization.

\section{Supplementary Information}

The online version contains supplementary material available at https://doi. org/10.1186/s12955-021-01874-x.

Additional file 1: Table S1. Socio-demographic characteristics of the study patients with differences in health-related quality of life (HRQoL) Table S2 Rheumatoid arthritis-related clinical characteristics of the study patients with differences in health-related quality of life ( $\mathrm{HRQOL}$ ) Table S3 Rheumatoid arthritis treatment characteristics of the study patients with differences in health-related quality of life (HRQOL). Table S4 Rheumatoid arthritis-related clinical characteristics of the study patients with differences in disability categories. Table S5 Rheumatoid arthritis treatment characteristics of the study patients with differences in disability categories.

\section{Acknowledgements}

The authors would like to thank the patients who participated in the survey.

\section{Authors' contributions}

DS collected data, conducted the literature search, assisted with data analysis, and helped write the manuscript. AB is involved in research conceptualization and data collection. AK interpreted the data and revised the manuscript for all new reviewers' concerns that have been addressed. SA and SZ were involved in research conceptualization, designed the study, supervised the survey team and data analysis, participated in data analysis and manuscript writing, provided critical data interpretation, and revised the manuscript in response to reviewers' comments. All authors read and approved the final manuscript. 


\section{Funding}

No funding was received for this study,

\section{Availability of data and materials}

Data and materials used in the study of this manuscript are available from the corresponding author upon request.

\section{Declarations}

\section{Ethics approval and consent to participate}

The Institutional Review Board (IRB) of An-Najah National University approved this study. All study participants provided verbal informed consent in compliance with the IRB requirement after they were told of the general objectives of the study and their confidentiality and privacy were assured. The ethics committee approved receiving only verbal consent. Since the study did not require any therapeutic intervention, participants were given informed verbal consent rather than written consent. Participation in this study was clearly below the minimum risk.

\section{Consent for publication}

Not applicable.

\section{Competing interests}

The authors declare that they have no competing interests.

\section{Author details}

'Department of Clinical and Community Pharmacy, College of Medicine and Health Sciences, An-Najah National University, Nablus 44839, Palestine. 2Department of Rheumatology, Jenin Government Hospital, Palestinian Ministry of Health, Jenin, Palestine. ${ }^{3}$ Division of Clinical Pharmacy, Hematology and Oncology Department, An-Najah National University Hospital, Nablus 44839, Palestine. ${ }^{4}$ Poison Control and Drug Information Center (PCDIC), College of Medicine and Health Sciences, An-Najah National University, Nablus 44839, Palestine. ${ }^{5}$ Clinical Research Centre, An-Najah National University Hospital, Nablus 44839, Palestine.

Received: 26 February 2021 Accepted: 30 September 2021

Published online: 13 October 2021

\section{References}

1. Aletaha D, Neogi T, Silman AJ, Funovits J, Felson DT, Bingham CO 3rd, Birnbaum NS, Burmester GR, Bykerk VP, Cohen MD, et al. 2010 Rheumatoid arthritis classification criteria: an American College of Rheumatology/ European League Against Rheumatism collaborative initiative. Arthritis Rheum. 2010:62(9):2569-81.

2. Kosinski M, Kujawski SC, Martin R, Wanke LA, Buatti MC, Ware JE Jr, Perfetto EM. Health-related quality of life in early rheumatoid arthritis: impact of disease and treatment response. Am J Manag Care. 2002;8(3):231-40.

3. Kvien TK. Epidemiology and burden of illness of rheumatoid arthritis. Pharmacoeconomics. 2004;22(2 Suppl 1):1-12.

4. Strand $V$, Khanna $D$. The impact of rheumatoid arthritis and treatment on patients' lives. Clin Exp Rheumatol. 2010;28(3 Suppl 59):S32-40.

5. Kvien TK, Uhlig T. Quality of life in rheumatoid arthritis. Scand J Rheumatol. 2005;34(5):333-41.

6. Michaud K, Wallenstein G, Wolfe F. Treatment and nontreatment predictors of health assessment questionnaire disability progression in rheumatoid arthritis: a longitudinal study of 18,485 patients. Arthritis Care Res (Hoboken). 2011;63(3):366-72.

7. van Vollenhoven R. Rheumatoid arthritis: Missed opportunities in the 2015 ACR guideline for RA treatment. Nat Rev Rheumatol. 2016;12(3):135-6.

8. Newsome G. Guidelines for the management of rheumatoid arthritis: 2002 update. J Am Acad Nurse Pract. 2002;14(10):432-7.

9. Maska L, Anderson J, Michaud K. Measures of functional status and quality of life in rheumatoid arthritis: Health Assessment Questionnaire Disability Index (HAQ), Modified Health Assessment Questionnaire (MHAQ), Multidimensional Health Assessment Questionnaire (MDHAQ), Health
Assessment Questionnaire II (HAQ-II), Improved Health Assessment Questionnaire (Improved HAQ), and Rheumatoid Arthritis Quality of Life (RAQoL). Arthritis Care Res (Hoboken). 2011:63(Suppl 11):S4-13.

10. Marra CA, Woolcott JC, Kopec JA, Shojania K, Offer R, Brazier JE, Esdaile $\mathrm{JM}$, Anis AH. A comparison of generic, indirect utility measures (the HUI2, HUI3, SF-6D, and the EQ-5D) and disease-specific instruments (the RAQOL and the HAQ) in rheumatoid arthritis. Soc Sci Med. 2005:60(7):1571-82.

11. Tugwell P, Wells G, Strand V, Maetzel A, Bombardier C, Crawford B, Dorrier C, Thompson A. Clinical improvement as reflected in measures of function and health-related quality of life following treatment with leflunomide compared with methotrexate in patients with rheumatoid arthritis: sensitivity and relative efficiency to detect a treatment effect in a twelve-month, placebo-controlled trial. Leflunomide Rheumatoid Arthritis Investigators Group. Arthritis Rheum. 2000;43(3):506-14.

12. Garip $Y$, Eser F, Bodur $H$. Health-related quality of life in rheumatoid arthritis: comparison of RAQoL with other scales in terms of disease activity, severity of pain, and functional status. Rheumatol Int. 2011;31(6):769-72.

13. Yaghoubi A, Tabrizi JS, Mirinazhad MM, Azami S, Naghavi-Behzad M, Ghojazadeh M. Quality of life in cardiovascular patients in Iran and factors affecting it: a systematic review. J Cardiovasc Thorac Res. 2012;4(4):95-101.

14. Zyoud SH, Daraghmeh DN, Mezyed DO, Khdeir RL, Sawafta MN, Ayaseh NA, Tabeeb GH, Sweileh WM, Awang R, Al-Jabi SW. Factors affecting quality of life in patients on haemodialysis: a cross-sectional study from Palestine. BMC Nephrol. 2016;17(1):44

15. Dreidi MM, Hamdan-Mansour AM. Pain, sleep disturbance, and quality of life among Palestinian patients diagnosed with cancer. J Cancer Educ 2016;31(4):796-803

16. Al-Jabi SW, Zyoud SH, Sweileh WM, Wildali AH, Saleem HM, Aysa HA, Badwan MA, Awang R. Relationship of treatment satisfaction to healthrelated quality of life: findings from a cross-sectional survey among hypertensive patients in Palestine. Health Expect. 2015;18(6):3336-48.

17. Zyoud SH, Al-Jabi SW, Sweileh WM, Wildali AH, Saleem HM, Aysa HA, Badwan MA, Awang R, Morisky DE. Health-related quality of life associated with treatment adherence in patients with hypertension: a crosssectional study. Int J Cardiol. 2013;168(3):2981-3.

18. Abu Farha NH, Khatib MT, Salameh H, Zyoud SH. Cancer-related posttreatment pain and its impact on health-related quality of life in breast cancer patients: a cross sectional study in Palestine. Asia Pac Fam Med. 2017;16:7.

19. Ahmad QT, Saffarini JH, Samara AM, Jabri DS, Safarini ZH, Banijaber YM, Jaradat A, Abushamma F, Zyoud SH. The impact of lower urinary tract symptoms on the quality of life during pregnancy: a cross-sectional study from Palestine. BMC Urol. 2020;20(1):191.

20. Barham A, Ibraheem R, Zyoud SH. Cardiac self-efficacy and quality of life in patients with coronary heart disease: a cross-sectional study from Palestine. BMC Cardiovasc Disord. 2019;19(1):290.

21. Khatib ST, Hemadneh MK, Hasan SA, Khazneh E, Zyoud SH. Quality of life in hemodialysis diabetic patients: a multicenter cross-sectional study from Palestine. BMC Nephrol. 2018;19(1):49.

22. Habib G, Artul S, Ratson N, Froom P. Household work disability of Arab housewives with rheumatoid arthritis. Clin Rheumatol. 2007;26(5):759-63.

23. Ibn Yacoub Y, Amine B, Laatiris A, Wafki F, Znat F, Hajiaj-Hassouni N. Prevalence of overweight in Moroccan patients with rheumatoid arthritis and its relationships with disease features. Clin Rheumatol. 2012;31(3):479-82.

24. Zou Y, Cheung PP, Teoh LK, Chen C, Lahiri M. Sociodemographic factors as determinants of disease, disability and quality of life trajectories in early rheumatoid arthritis: A multi-ethnic inception cohort study. Int J Rheum Dis. 2020;23(1):55-64.

25. Katchamart W, Narongroeknawin $\mathrm{P}$, Chanapai W, Thaweeratthakul P. Health-related quality of life in patients with rheumatoid arthritis. BMC Rheumatol. 2019:3:34

26. Zhou Y, Wang X, An Y, Zhang X, Han S, Li X, Wang L, Wang C, Wang Y, Yang $R$, et al. Disability and health-related quality of life in Chinese patients with rheumatoid arthritis: a cross-sectional study. Int J Rheum Dis. 2018:21(9):1709-15.

27. Bai B, Chen M, Fu L, Liu H, Jin L, Wei T, Xin F. Quality of life and influencing factors of patients with rheumatoid arthritis in Northeast China. Health Qual Life Outcomes. 2020;18(1):119.

28. Bae SC, Cho SK, Won S, Lee HS, Lee SH, Kang YM, Lee SH, Lee YA, Choe JY, Chung WT, et al. Factors associated with quality of life and functional 
disability among rheumatoid arthritis patients treated with diseasemodifying anti-rheumatic drugs for at least 6 months. Int J Rheum Dis. 2018;21(5):1001-9.

29. Xavier RM, Zerbini CAF, Pollak DF, Morales-Torres JLA, Chalem P, Restrepo JFM, Duhau JA, Amado JR, Abello M, de la Vega MC, et al. Burden of rheumatoid arthritis on patients' work productivity and quality of life. Adv Rheumatol. 2019;59(1):47.

30. Zhang L, Cai P, Zhu W. Depression has an impact on disease activity and health-related quality of life in rheumatoid arthritis: a systematic review and meta-analysis. Int J Rheum Dis. 2020;23(3):285-93.

31. Awada S, Ajrouche R, Shoker M, Al-Hajje A, Rachidi S, Zein S, Bawab W. Rheumatoid arthritis in the lebanese adults: impact on health-related quality of life. J Epidemiol Glob Health. 2019;9(4):281-7.

32. Mandal M, Dasgupta A, Dutt D, Taraphdar P, Ghosh P, Paul B. Quantification of health-related quality of life among patients with rheumatoid arthritis: an institution-based study in Kolkata, West Bengal. J Family Med Prim Care. 2020;9(8):3970-6.

33. Seca S, Kirch S, Cabrita AS, Greten HJ. Evaluation of the effect of acupuncture on hand pain, functional deficits and health-related quality of life in patients with rheumatoid arthritis - a study protocol for a multicenter, double-blind, randomized clinical trial. J Integr Med. 2016;14(3):219-27.

34. EuroQol Group. EQ-5D-5L User Guide: Basic information on how to use the EQ-5D-5L instrument 2013. http://www.euroqol.org/fileadmin/user_ upload/Documenten/PDF/Folders_Flyers/UserGuide_EQ-5D-5L_V2.0_ October_2013.pdf. Accessed 2 Jan 2017.

35. Aburuz S, Bulatova N, Twalbeh M, Gazawi M. The validity and reliability of the Arabic version of the EQ-5D: a study from Jordan. Ann Saudi Med. 2009;29(4):304-8.

36. Fries JF, Spitz P, Kraines RG, Holman HR. Measurement of patient outcome in arthritis. Arthritis Rheum. 1980;23(2):137-45.

37. Dr R, Fries JF, Singh G. The health assessment questionnaire 1995—status and review. In: Spilker B, editor. Quality of life and pharmacoleconomics in clinical trials. 2nd ed. Philadelphia: Lippincott-Raven Publication; 1996.

38. Stanford University Medical Center. The Arthritis, Rheumatism, and Aging Medical Information System. 2009. http://aramis.stanford.edu/downl oads/HAQ\%20Instructions\%20(ARAMIS)\%206-30-09.pdf. Accessed 23 Jan 2014.

39. Bruce B, Fries JF. The Health Assessment Questionnaire (HAQ). Clin Exp Rheumatol. 2005;23(5 Suppl 39):S14-18.

40. El Meidany YM, El Gaafary MM, Ahmed I. Cross-cultural adaptation and validation of an Arabic Health Assessment Questionnaire for use in rheumatoid arthritis patients. Joint Bone Spine. 2003;70(3):195-202.

41. Bruce B, Fries JF. The Stanford Health Assessment Questionnaire: dimensions and practical applications. Health Qual Life Outcomes. 2003;1:20.

42. Vittecoq O, Pouplin S, Krzanowska K, Jouen-Beades F, Menard JF, Gayet A, Daragon A, Tron F, Le Loet X. Rheumatoid factor is the strongest predictor of radiological progression of rheumatoid arthritis in a three-year prospective study in community-recruited patients. Rheumatology (Oxford). 2003;42(8):939-46.

43. Samoudi AF, Marzouq MK, Samara AM, Zyoud SH, Al-Jabi SW. The impact of pain on the quality of life of patients with end-stage renal disease undergoing hemodialysis: a multicenter cross-sectional study from Palestine. Health Qual Life Outcomes. 2021;19(1):39.

44. Zyoud SeH, Daraghmeh DN, Mezyed DO, Khdeir RL, Sawafta MN, Ayaseh NA, Tabeeb GH, Sweileh WM, Awang R, Al-Jabi SW. Quality of life in Palestinian patients with end-stage renal disease receiving treatment by haemodialysis: a cross-sectional study. The Lancet. 2018;391:S32.

45. Cross M, Smith E, Hoy D, Carmona L, Wolfe F, Vos T, Williams B, Gabriel $\mathrm{S}$, Lassere M, Johns N, et al. The global burden of rheumatoid arthritis: estimates from the global burden of disease 2010 study. Ann Rheum Dis. 2014;73(7):1316-22.

46. Namas R, Joshi A, Ali Z, Al Saleh J, Abuzakouk M. Demographic and clinical patterns of rheumatoid arthritis in an emirati cohort from United Arab Emirates. Int J Rheumatol. 2019;2019:3057578.

47. Attar SM. Hyperlipidemia in rheumatoid arthritis patients in Saudi Arabia. Correlation with C-reactive protein levels and disease activity. Saudi Med J. 2015;36(6):685-91.

48. Karimi S, Yarmohammadian MH, Shokri A, Mottaghi P, Qolipour K, Kordi A, Bahman Ziari N. Predictors and effective factors on quality of life among Iranian patients with rheumatoid arthritis. Mater Sociomed. 2013:25(3):158-62.
49. Geryk LL, Carpenter DM, Blalock SJ, DeVellis RF, Jordan JM. The impact of co-morbidity on health-related quality of life in rheumatoid arthritis and osteoarthritis patients. Clin Exp Rheumatol. 2015;33(3):366-74.

50. Matcham F, Scott IC, Rayner L, Hotopf M, Kingsley GH, Norton S, Scott $D L$, Steer $S$. The impact of rheumatoid arthritis on quality-of-life assessed using the SF-36: a systematic review and meta-analysis. Semin Arthritis Rheum. 2014;44(2):123-30.

51. Sorensen J, Linde L, Ostergaard M, Hetland ML. Quality-adjusted life expectancies in patients with rheumatoid arthritis-comparison of index scores from EQ-5D, 15D, and SF-6D. Value Health. 2012;15(2):334-9.

52. Pentek M, Szekanecz Z, Czirjak L, Poor G, Rojkovich B, Polgar A, Genti G, Kiss CG, Sandor Z, Majer I, et al. Impact of disease progression on health status, quality of life and costs in rheumatoid arthritis in Hungary. Orv Hetil. 2008;149(16):733-41.

53. Cho SK, Kim D, Jun JB, Bae SC, Sung YK. Factors influencing quality of life (QOL) for Korean patients with rheumatoid arthritis (RA). Rheumatol Int. 2013;33(1):93-102.

54. Hoshi D, Tanaka E, Igarashi A, Inoue E, Kobayashi A, Sugimoto N, Shidara K, Sato E, Seto Y, Nakajima A, et al. Profiles of EQ-5D utility scores in the daily practice of Japanese patients with rheumatoid arthritis; Analysis of the IORRA database. Mod Rheumatol. 2016;26(1):40-5.

55. Arne M, Janson C, Janson S, Boman G, Lindqvist U, Berne C, Emtner M. Physical activity and quality of life in subjects with chronic disease: chronic obstructive pulmonary disease compared with rheumatoid arthritis and diabetes mellitus. Scand J Prim Health Care. 2009;27(3):141-7.

56. Gong G, Mao J. Health-related quality of life among Chinese patients with rheumatoid arthritis: the predictive roles of fatigue, functional disability, self-efficacy, and social support. Nurs Res. 2016;65(1):55-67.

57. Linde L, Sorensen J, Ostergaard M, Hetland ML. Health-related quality of life of patients with rheumatoid arthritis. Which factors are of signifcance? Ugeskr Laeger. 2008;170(10):855-8.

58. GroessI EJ, Ganiats TG, Sarkin AJ. Sociodemographic differences in quality of life in rheumatoid arthritis. Pharmacoeconomics. 2006;24(2):109-21.

59. Gamal RM, Mahran SA, El Fetoh NA, Janbi F. Quality of life assessment in Egyptian rheumatoid arthritis patients: relation to clinical features and disease activity. Egypt Rheumatol. 2016;38(2):65-70.

60. Purabdollah M, Lakdizaji S, Rahmani A, Hajalilu M, Ansarin K. Relationship between sleep disorders, pain and quality of life in patients with rheumatoid arthritis. J Caring Sci. 2015;4(3):233-41.

61. Sariyildiz MA, Batmaz I, Bozkurt M, Bez Y, Cetincakmak MG, Yazmalar L, Ucar D, Celepkolu T. Sleep quality in rheumatoid arthritis: relationship between the disease severity, depression, functional status and the quality of life. J Clin Med Res. 2014;6(1):44-52.

62. Al-Bishri J, Attar S, Bassuni N, Al-Nofaiey Y, Qutbuddeen H, Al-Harthi S, Subahi S. Comorbidity profile among patients with rheumatoid arthritis and the impact on prescriptions trend. Clin Med Insights Arthritis Musculoskelet Disord. 2013;6:11-8.

63. Inotai A, Rojkovich B, Fulop A, Jaszay E, Agh T, Meszaros A. Health-related quality of life and utility in patients receiving biological and non-biological treatments in rheumatoid arthritis. Rheumatol Int. 2012;32(4):963-9.

64. Kopciuch D, Paczkowska A, Leszczynsk P, Michalak M, Nowakowskai E. Effect of therapy with anti-TNF alpha drugs and DMARD on disease activity and health related quality of life among women with rheumatoid arthritis. Acta Pol Pharm. 2016;73(2):547-54.

65. Abalos Medina GM, Ruiz Villaverde G, Sanchez Cano D, Ruiz Villaverde R, Ramirez Rodrigo J, Raya Alvarez E, Villaverde Gutierrez C. The impact of therapy with TNF-blockers on health-related quality of life in rheumatoid arthritis patients. A pilot study. Reumatol Clin. 2011;7(3):167-71.

66. Dhillon S, Lyseng-Williamson KA, Scott $\sqcup$. Etanercept: a review of its use in the management of rheumatoid arthritis. Drugs. 2007;67(8):1211-41.

67. Hassan WA, Baraka EA, Fouad NA. Clinical significance of soluble programmed death-1 (SPD-1) in rheumatoid arthritis patients: Relation to disease activity and functional status. Egypt Rheumatol. 2015:37(4):165-9.

68. Mostafa H, Radwan A. The relationship between disease activity and depression in Egyptian patients with rheumatoid arthritis. Egypt Rheumatol. 2013;35(4):193-9.

69. Ibn Yacoub Y, Amine B, Laatiris A, Wafki F, Znat F, Hajjaj-Hassouni N. Fatigue and severity of rheumatoid arthritis in Moroccan patients. Rheumatol Int. 2012;32(7):1901-7. 
70. Asma K, Hèla Z, Hosni B, Najla A, Habib A, Imène B, Boutheina K, Elyes B. Quality of life in tunisian patients with rheumatoid arthritis: a crosssectional study about 200 patients. Ann Rheum Dis. 2013;71(Suppl 3):654.

71. Zhao S, Chen Y, Chen H. Sociodemographic factors associated with functional disability in outpatients with rheumatoid arthritis in Southwest China. Clin Rheumatol. 2015;34(5):845-51.

72. Norton S, Fu B, Scott DL, Deighton C, Symmons DP, Wailoo AJ, Tosh J, Lunt M, Davies R, Young A, et al. Health Assessment Questionnaire disability progression in early rheumatoid arthritis: systematic review and analysis of two inception cohorts. Semin Arthritis Rheum. 2014;44(2):131-44.

73. Camacho EM, Verstappen SM, Lunt M, Bunn DK, Symmons DP. Influence of age and sex on functional outcome over time in a cohort of patients with recent-onset inflammatory polyarthritis: results from the Norfolk Arthritis Register. Arthritis Care Res (Hoboken). 2011;63(12):1745-52.

74. Innala L, Berglin E, Moller B, Ljung L, Smedby T, Sodergren A, Magnusson S, Rantapaa-Dahlqvist S, Wallberg-Jonsson S. Age at onset determines severity and choice of treatment in early rheumatoid arthritis: a prospective study. Arthritis Res Ther. 2014;16(2):R94.

75. Krams T, Ruyssen-Witrand A, Nigon D, Degboe Y, Tobon G, Fautrel B, Berenbaum F, Cantagrel A, Constantin A. Effect of age at rheumatoid arthritis onset on clinical, radiographic, and functional outcomes: the ESPOIR cohort. Joint Bone Spine. 2016;83(5):511-5.

76. El-Hadary HF, Hadidi KT, Abdallah MA. Factors related to disability in Egyptian rheumatoid patients. Cairo: Cairo University; 2001.

77. van Onna M, Boonen A. The challenging interplay between rheumatoid arthritis, ageing and comorbidities. BMC Musculoskelet Disord. 2016;17:184.

78. Yazici Y, Pincus T, Kautiainen H, Sokka T. Morning stiffness in patients with early rheumatoid arthritis is associated more strongly with functional disability than with joint swelling and erythrocyte sedimentation rate. J Rheumatol. 2004;31(9):1723-6.

79. Rupinski R, Filipowicz-Sosnowska A. Disease activity and functional disability in rheumatoid arthritis patients. Anna Filipowicz-Sosnowska Ru. 2005;43(3):129-37.
80. Luyster FS, Chasens ER, Wasko M, Dunbar-Jacob J. Sleep quality and functional disability in patients with rheumatoid arthritis. J Clin Sleep Med. 2011;7(1):49-55.

81. Abad VC, Sarinas PS, Guilleminault C. Sleep and rheumatologic disorders. Sleep Med Rev. 2008;12(3):211-28

82. Radner H, Smolen JS, Aletaha D. Impact of comorbidity on physical function in patients with rheumatoid arthritis. Ann Rheum Dis. 2010;69(3):536-41.

83. Radner H, Smolen JS, Aletaha D. Comorbidity affects all domains of physical function and quality of life in patients with rheumatoid arthritis. Rheumatology. 2011;50(2):381-8.

84. Genovese MC, Bathon JM, Martin RW, Fleischmann RM, Tesser JR, Schiff MH, Keystone EC, Wasko MC, Moreland LW, Weaver AL, et al. Etanercept versus methotrexate in patients with early rheumatoid arthritis: two-year radiographic and clinical outcomes. Arthritis Rheum. 2002;46(6):1443-50.

85. Baumgartner SW, Fleischmann RM, Moreland LW, Schiff MH, Markenson J, Whitmore JB. Etanercept (Enbrel) in patients with rheumatoid arthritis with recent onset versus established disease: improvement in disability. J Rheumatol. 2004;31(8):1532-7.

86. Aberumand B, Barra L, Cao Y, Riche NL, Thompson AE, Rohekar G, Rohekar $\mathrm{S}$, Bonner A, Pope JE. Response to tumor necrosis factor inhibitors in rheumatoid arthritis for function and pain is affected by rheumatoid factor. Open Rheumatol J. 2014;8:73-6.

87. Fleischmann R, Baumgartner S, Moreland L, Schiff M, Markenson J, Spencer-Green G. Improvement of disability in ra patients with early vs established disease after treatment with enbre ${ }^{\circledR}$ (etanercept). Ann Rheum Dis. 2001;60(Suppl 1):A478.

\section{Publisher's Note}

Springer Nature remains neutral with regard to jurisdictional claims in published maps and institutional affiliations.
Ready to submit your research? Choose BMC and benefit from:

- fast, convenient online submission

- thorough peer review by experienced researchers in your field

- rapid publication on acceptance

- support for research data, including large and complex data types

- gold Open Access which fosters wider collaboration and increased citations

- maximum visibility for your research: over $100 \mathrm{M}$ website views per year

At BMC, research is always in progress.

Learn more biomedcentral.com/submissions 